\title{
P02.72. A pilot investigation of alignment-based yoga for pediatric obesity
}

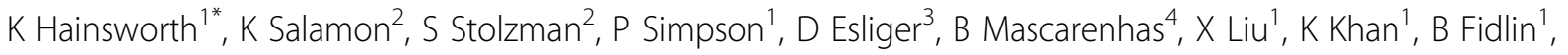 \\ S Weisman ${ }^{1}$
}

From International Research Congress on Integrative Medicine and Health 2012

Portland, Oregon, USA. 15-18 May 2012

\section{Purpose}

Although exercise is a primary tool for weight reduction, recent findings of aberrant biomechanics in obese youth have raised concern over traditional exercise prescriptions. Given that injury and disability often act as barriers to physical activity (PA), particularly for those with increased weight, safe and appealing interventions are urgently needed. To that end, this study examined the benefits of a yoga intervention for obese adolescents.

\section{Methods}

Adolescents referred to a pediatric weight management clinic (BMI $>95$ th percentile and $\geq 1$ co-morbidity) were recruited to participate in an 8-week study involving biweekly, 60-minute Iyengar style yoga classes. All questionnaires and assessments of physical functioning were conducted immediately before and after the 8-week intervention. Assessments included prior experience and expectations, health-related quality of life (HRQOL), state anxiety, and functional limitations. Standardized assessments of participants' physical abilities included push-ups, sit-ups, a step test, and sit to reach. PA levels were objectively assessed using a hip-mounted Actical accelerometer worn 7 consecutive days (pre and postyoga).

\section{Results}

Sixteen youth (11-17 years, M 13) attended at least 7 classes. Half reported experiencing pain in the 2 weeks prior to consent (usual pain intensity M $5.88 \pm 2.30$ ). Sitto-reach improved $(\mathrm{p}<.05)$ from pre $(\mathrm{M} 6.20 \mathrm{~cm} \pm 8.86)$ to post $(\mathrm{M} 8.83 \mathrm{~cm} \pm 5.62)$ intervention. Across almost all domains, participant and parent reports of HRQOL

${ }^{1}$ Medical College of Wisconsin, Milwaukee, USA

Full list of author information is available at the end of the article significantly improved (p's < .05). Self-reports of stateanxiety decreased $(\mathrm{p}<.05)$. Whereas time spent in Sedentary, Light and Vigorous PA did not change, time spent in Moderate intensity PA increased $(\mathrm{p}=.05)$ from pre- $(\mathrm{M}$ $21.82 \mathrm{~min}$. per day \pm 25.71 ) to post-yoga (M $27.26 \mathrm{~min}$. per day \pm 16.44 ) intervention.

\section{Conclusion}

These preliminary findings are encouraging, and suggest that alignment-based yoga may be a safe and effective intervention for pediatric obesity.

\section{Author details}

${ }^{1}$ Medical College of Wisconsin, Milwaukee, USA. ${ }^{2}$ Children's Hospital of Wisconsin, Milwaukee, USA. ${ }^{3}$ University of Saskatchewan, Saskatchewan, Canada. ${ }^{4}$ Santosh Yoga, LLC, Wauwatosa, USA.

Published: 12 June 2012

doi:10.1186/1472-6882-12-S1-P128

Cite this article as: Hainsworth et al: P02.72. A pilot investigation of alignment-based yoga for pediatric obesity. BMC Complementary and Alternative Medicine 2012 12(Suppl 1):P128.

Submit your next manuscript to BioMed Central and take full advantage of:

- Convenient online submission

- Thorough peer review

- No space constraints or color figure charges

- Immediate publication on acceptance

- Inclusion in PubMed, CAS, Scopus and Google Scholar

- Research which is freely available for redistribution

\section{(Ciomed Central}

